\title{
How to Improve the Quality of Teaching in the Course of Network Education
}

\author{
Na Qiao ${ }^{1}$,Haoyan Shao ${ }^{1}$,Xiaohui Zhang ${ }^{2}$ \\ ${ }^{I}$ Dalian University of Technology, Dalian,116023,PR China \\ ${ }^{2}$ School of Computer and Information Technology, Dalian,116023,PR China
}

\begin{abstract}
This paper expounds the characteristics and advantages of modern distance education. On this basis, this paper puts forward the limitations and deficiencies of the current educational practice, and analyzes the reasons that affect the quality of education. On the basis of analyzing the reasons, solutions to the problems in the course of work are put forward according to working experience and practice. The realization of the virtual experiment will ease difficulties and pressures effectively, which the various modern distance education in colleges and universities generally faced in funds, venues and equipment and other aspects. So carrying out the virtual experimental teaching is timeless and beyond the constraint of space, and help to improve the quality of teaching. Therefore, the virtual experiment will become an inevitable trend in the practice teaching of modern distance education.
\end{abstract}

With the development of modern information technology, modern distance education is a new form of education, which is the main means to build a lifelong learning system in the era of knowledge economy. It can exploit the advantages of various educational resources to the full, and provide strong support for improving the quality of education, and provide a convenient, fast and wide range of educational services to different people. With the advent of the information age, the era of knowledge economy, the rapid development of science and technology, and emerging industries continue to emerge and develop, people must continue to learn, lifelong learning. Therefore, modern distance education is responsible for improving the quality of the whole people and promoting the development of economy and society. In the new situation, we must repositioning of the modern distance education, reunderstanding of modern distance education, and reunderstanding of the practice of modern distance education, to explore the teaching mode of modern remote education.

\section{Characteristics and advantages of modern distance education}

\subsection{Maximizing the use of resources}

A variety of educational resources across the space constraints through the network, so that the school education can become more open to the wider area of radiation than the open education. Schools can give full play to their own strengths and advantages of educational resources, the best teachers, and spread the best teaching results through the network to all directions.

\subsection{Autonomous learning behavior}

The application of network technology to distance education is characterized by: any person, any time, any place, starting from any chapter, learning any course. Network education is convenient and flexible, "any of the five", is the most direct manifestation of the active learning characteristics, and meet the needs of modern education and lifelong education fully.

\subsection{Interactive learning}

It can carry out a full range of communication through the network, narrow the psychological distance ,and increase the exchange of opportunities and scope between teachers and students, or students and students. We can carry on the statistical analysis about question type, the number, the frequency through the computer to the student, cause the teacher to understand the students' questions, the difficulty and the main question in the study, more targeted to instruct the student.

\subsection{Personalized teaching}

In distance education, we can apply the information database management technology and two-way interactive function in computer network lock. On the one hand, tracking system for each network, the character information, learning process and stage can achieve complete, on the other hand, the system of teaching and learning service system can propose personalized learning suggestions according to the records of personal data and different students. 


\subsection{Teaching management automation}

The computer network teaching management platform has the function of automatic management and remote interactive processing.

Remote students' counseling, registration, payment, course selection, query, school management, operation and examination management, etc., can be completed through the network remote interaction.

\section{The modern distance education in the lack of time and analysis of reasons}

Practice is the essence of modern educational thought, and it is widely used in various forms of education, especially for the cultivation of applied talents in vocational education and adult education. Practice is the basic way to carry out the practical education thought, to cultivate the learning ability, practical ability and innovation ability, which plays an important role in the teaching process. But there are still many problems in the practice of education, the existence of such problems, makes a lot of problems still exist in current education practice link, the existence of such problems, the current practice of distance education link requirements vary greatly, the task is far from complete, which seriously restrict the improvement of the quality of education. In general, the impact of the practice of the reasons for the completion of the following points:

\subsection{Distance education object is mainly the general public on the job}

Now the social conditions, due to various social reasons, many people study is still relatively backward to stay in to get a diploma, lack of awareness of the importance of various abilities, training does not attach importance to the ability of learning is the exam, only by rote. As a result, we do not attach importance to the practice of training ability does not, do not participate in the practice and implementation of the impact of the implementation of the effect.

\subsection{Difficult to organize the school}

First, the distance education is a joint form of education, a variety of forces to form a joint force more difficult. In addition, there are still some problems in running a school, such as: College away from students, etc. Austrian education provides only a learning platform, its strength is relatively weak.

\subsection{Practice is difficult}

Students do not have too much time, learning center staff is less, lack of manpower, no base, lack of material conditions. The work is not mature and fixed mode, cannot be quantified, unable to assess and manage.

\subsection{Concept problem}

The social and educational groups are not aware of the importance of the practice education, have not realized the important influence of the link to the teaching effect, and have not enough understanding of the importance of improving the quality of teaching. So there is no need, no pressure, no confidence and courage, no initiative to overcome the difficulties of enthusiasm.

\section{The solution of modern distance education}

The practice of engineering education is indispensable part of the teaching process, but also a weak link in the development of modern distance education, now, it has become a constraint weak link in the development of distance education, which has become the bottleneck of current distance education engineering professional development. In the modern distance education practice teaching, in addition to the traditional practice teaching mode must be used, it should give full play to the advantages of modern distance education technology network advantages and modern management advantages, combined with the characteristics of education objects, continuous innovation and appropriate new practical teaching mode. In modern distance education, the feasibility of small students personally from universities in the real laboratory experiments, so the creation of online virtual experiment course has become an inevitable trend to carry out the experiment teaching in modern distance education..

The development and application of the virtual laboratory on the Internet has played an important role in making up the resources and enhancing the teaching effect. After several years of exploration and practice, the school of continuing education of Dalian University of Technology has introduced a virtual experiment model to solve the problem of difficult to realize in practice. Virtual laboratory can save the classroom practice of virtual experiment, practice less funding, less material, easy preparation, high safety, can be more intuitive to let students understand the knowledge, enhance the perceptual knowledge, can be very good to attract the attention of students, so as to achieve better teaching effect; the vivid image, can be flexible, can effectively improve the students' interest in learning, which is helpful for students to understand and master the knowledge; virtual experiment teaching can be closely linked, is conducive to the breakthrough teaching difficulty, help to validate the concepts and knowledge, is not easy to understand in the textbook problem; in addition, the virtual experiment for teacher edge demonstration while explaining, to guide the students to grasp the key, break through the difficulty, consolidation points.

In the practice of the introduction of virtual experiments, for civil engineering, road and bridge engineering, water conservancy projects, as well as marine and marine engineering, such as the implementation of the customer 
based professional practice teaching is of great significance.

In this paper, a virtual experiment of soil mechanics experiment base on network environment is used to illustrate the important role of virtual laboratory in modern education. It is difficult for students to remember the experimental conditions and precautions only from the learning materials, and it is difficult to form a complete and clear process in mind, theory and practice very hard in the process of learning is very good with. In view of this reason, the real environment can be recorded in the experimental or operational process into a video, so that students can understand the specific operation of the experiment by watching the video to complete the experimental report. Figure $1 \sim 4$ is a fragment of the experiment.
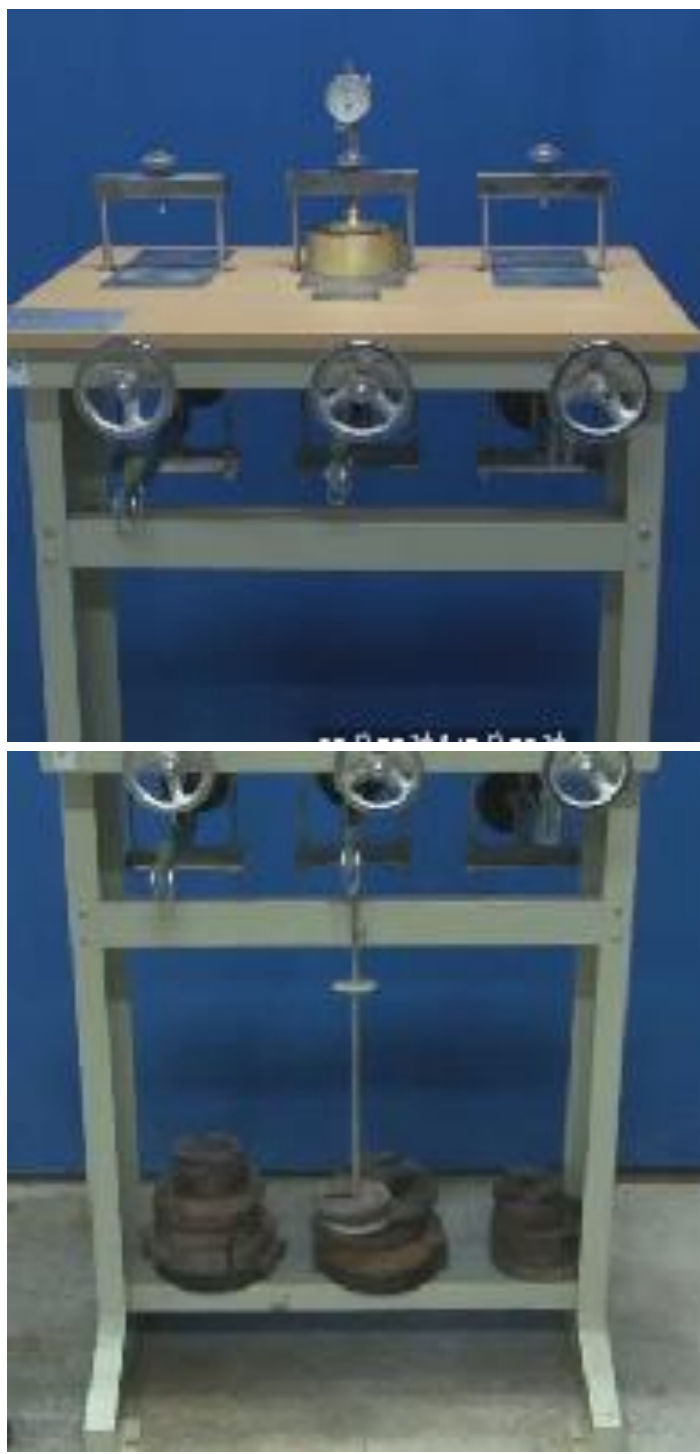

Fig. 1. Experimental instrumentations of soil mechanics experiment

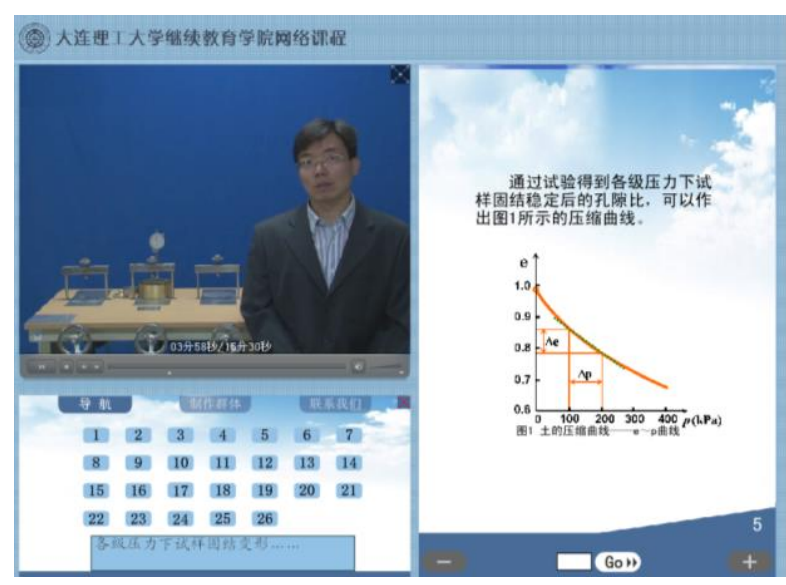

Fig. 2.Sketch of soil compression curve

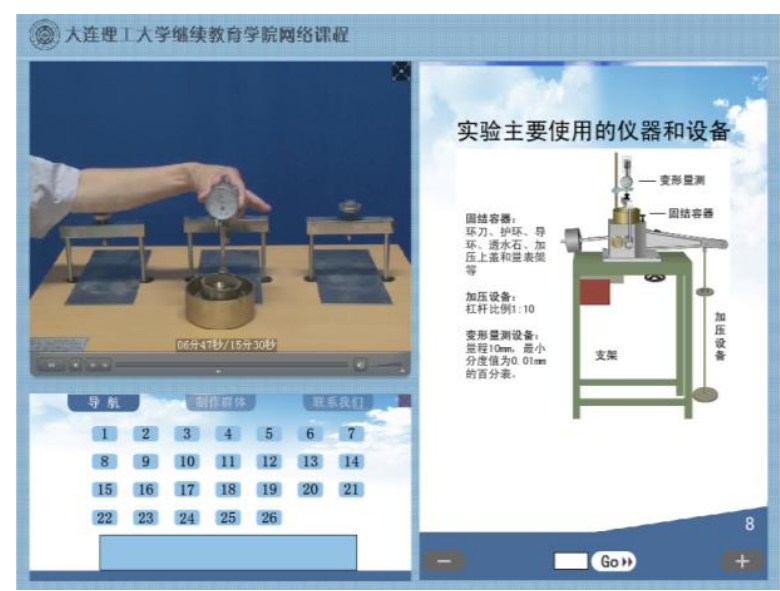

Fig. 3.Visualizations of experimental instrumentations

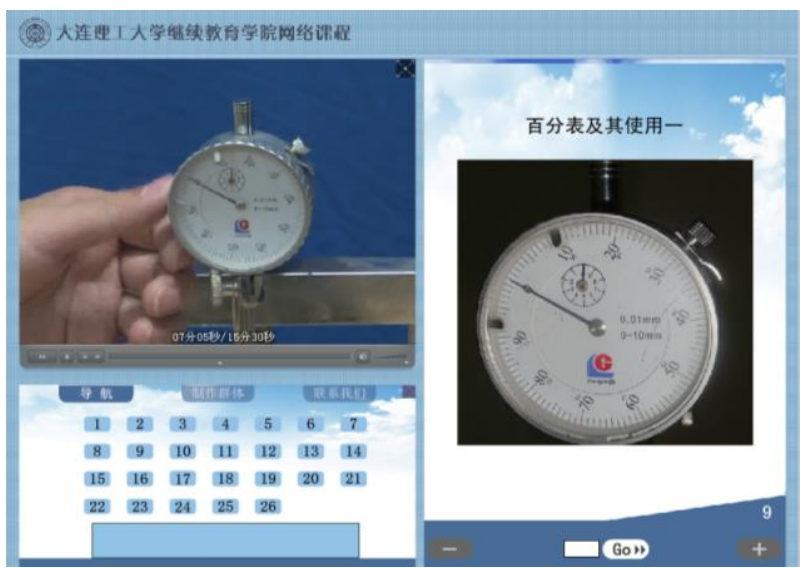

Fig. 4.Example of percentmeter

\section{Conclusion}

Based on the characteristics of modern distance education, this paper puts forward the problems in practice, and puts forward the method of making use of virtual experiment on the Internet to make up for the defects of the link. The practice and experiment combination can make full use of distance education multimedia experimental video resources, low cost, short production cycle, although unable to achieve the same results and real experiments, but the learners can still 
pass the video has a profound perceptual knowledge of experimental course, it can greatly improve the network education the effect has become indispensable tools in modern distance education mode.

\section{References}

1. Shuqin Lou, Xinzhi Sheng. Design and development of Digital electronic technology foundation base on network course $[\mathrm{J}]$. Chinese distance education, 2002(3). (In Chinese)

2. Qibiao Deng. Advantages and characteristics of modern distance education [J]. Journal of Fujian Radio \& TV University, 2002(4). (In Chinese)

3. Xiaoliang Zhao, Xinfeng Cui. Analysis of the concept、characteristics and development trends of modern distance education [J]. Techno-economic market, 2010(4). (In Chinese)

4. Hong Wei,Wei Hui. Construction and Practice of Distance Education in Engineering Practice Instructional Modes [J]. Technology and Education, 2010(6). (In Chinese) 